\title{
Identification of a novel locus, $B P H 38(t)$, conferring resistance to brown planthopper (Nilaparvata lugens Stal.) using early backcross population in rice (Oryza sativa L.)
}

\author{
C. H. Balachiranjeevi • G. D. Prahalada • A. Mahender • Md. Jamaloddin • \\ M. A. L. Sevilla - C. M. Marfori-Nazarea - R. Vinarao - U. Sushanto • \\ S. E. Baehaki $\cdot$ Z. K. Li $\cdot$ J. Ali $i$
}

Received: 12 March 2019/Accepted: 26 September 2019/Published online: 10 October 2019

(C) The Author(s) 2019

\begin{abstract}
Rice is the most important staple food crop, and it feeds more than half of the world population. Brown planthopper (BPH) is a major insect pest of rice that causes $20-80 \%$ yield loss through direct and indirect damage. The identification and use of $\mathrm{BPH}$ resistance genes can efficiently manage BPH. A molecular marker-based genetic analysis of $\mathrm{BPH}$ resistance was carried out using 101 $\mathrm{BC}_{1} \mathrm{~F}_{5}$ mapping population derived from a cross between a BPH-resistant indica variety Khazar and
\end{abstract}

Electronic supplementary material The online version of this article (https://doi.org/10.1007/s10681-019-2506-2) contains supplementary material, which is available to authorized users.

C. H. Balachiranjeevi · A. Mahender .

Md. Jamaloddin - M. A. L. Sevilla . C. M. Marfori-

Nazarea $\cdot$ R. Vinarao $\cdot$ J. Ali $(\bowtie)$

Rice Breeding Platform, International Rice Research Institute, DAPO Box 7777, Metro Manila, Philippines e-mail: j.ali@irri.org

\section{G. D. Prahalada}

Strategic Innovation Platform, International Rice

Research Institute, DAPO Box 7777, Metro Manila, Philippines

U. Sushanto - S. E. Baehaki

Indonesian Center for Rice Research, Sukamandi, Indonesia

Z. K. Li

Chinese Academy of Agricultural Sciences, Beijing, China an elite BPH-susceptible line Huang-Huan-Zhan. The genetic analysis indicated the existence of Mendelian segregation for BPH resistance. A total of 702 highquality polymorphic single nucleotide polymorphism (SNP) markers, genotypic data, and precisely estimated BPH scores were used for molecular mapping, which resulted in the identification of the $B P H 38(\mathrm{t})$ locus on the long arm of chromosome 1 between SNP markers 693,369 and id 10,112,165 of $496.2 \mathrm{~kb}$ in size with LOD of 20.53 and phenotypic variation explained of $35.91 \%$. A total of 71 candidate genes were predicted in the detected locus. Among these candidate genes, LOC_Os01g37260 was found to belong to the FBXL class of F-box protein possessing the LRR domain, which is reported to be involved in biotic stress resistance. Furthermore, background analysis and phenotypic selection resulted in the identification of introgression lines (ILs) possessing at least $90 \%$ recurrent parent genome recovery and showing superior performance for several agro-morphological traits. The BPH resistance locus and ILs identified in the present study will be useful in marker-assisted $\mathrm{BPH}$ resistance breeding programs.

Keywords Brown planthopper - QTL mapping · Resistance $\cdot$ MAS $\cdot$ Early backcross population 


\section{Introduction}

Rice is an essential cereal crop that feeds more than 3.5 billion people globally. There is a need to increase rice production by up to $42 \%$ by 2025 to feed the everincreasing population (Seck et al. 2012; Ray et al. 2013). Additionally, about $52 \%$ of world rice production is lost annually because of living organisms, of which approximately $21 \%$ alone is contributed by the incidence of insect pests (Khush 1979; Sogawa et al. 2003). Among these insect pests, brown planthopper (BPH; Nilaparvata lugens Stal.) is one of the major devastating sap-sucking pests, prevalent throughout the rice-growing countries of Asia (Normile 2008). BPH causes significant damage to the rice crop by sucking sap from the xylem and phloem tissues, which ultimately leads to "hopperburn" and, hence, eventually complete yield loss. Besides the direct damage caused by BPH, it causes indirect damage by transmitting viruses (rice grassy stunt virus and ragged stunt virus) that also results in a yield penalty (Sogawa1982; Cha et al. 2008; Cabauatan et al. 2009).

Different pest management strategies are available to manage the damage caused by insect pests, including chemical control, improving field practices, and developing and cultivating resistant varieties. However, excessive use of chemicals for BPH management is hazardous to human health, cost-ineffective; and unsafe for the environment and natural biodiversity. Additionally, these chemicals would increase pest outbreak incidences as they can kill the natural predators and their competitors, which feed on BPH (Tanaka et al. 2000). Alternatively, the most durable, precise, and environmentally friendly strategy is to develop a sustainable host-plant resistance management system, which makes it possible to reduce pest incidence, maintain ecological fitness, and keep infestation below economic threshold levels (Brar et al. 2009).

To date, $37 \mathrm{BPH}$ resistance genes have been reported from different resistance sources ( $\mathrm{Li}$ et al. 2019; Yang et al. 2019; Yuexiong et al. 2019). Notably, the majority of the BPH resistance genes are mapped on six of the 12 chromosomes $(2,3,4,6$, 11, and 12) and, reportedly, four clusters of $\mathrm{BPH}$ resistance loci are located on three chromosomes. Cluster A is located on the long arm of chromosome12 and contains eight loci. Clusters B and D are located on the short and long arm of chromosome 4 containing 13 and four QTL/gene loci, respectively, including the recently identified $\mathrm{BPH} 34, \mathrm{BPH} 30$, and $\mathrm{BPH} 36$ resistance genes located on chromosome 4 (Li et al. 2019; Wang et al. 2018; Kumar et al. 2018). Cluster C is located on the short arm of chromosome 6, which includes six gene loci (Fujita et al. 2013). Out of 34 $\mathrm{BPH}$ resistance genes, 20 genes were fine mapped and only eight were cloned and characterized $(B P H 14$, BPH17, BPH18, BPH26, BPH29, BPH9, BPH32, and BPH6) (Du et al. 2009; Tamura et al. 2014; Liu et al. 2015; Wang et al. 2015; Ji et al. 2016; Ren et al. 2016; Zhao et al. 2016; Guo et al. 2018). Wang et al. (2018) mapped BPH3O by using $\mathrm{F}_{2: 3}$ populations AC1613/ 9311 and fine mapped by using backcrossed population on the short arm of the chromosome 4. Later, population derived from Kangwengingzhan/RBPH16 and HHZ/RBPH17 (lines RBHH16 and RBPH17 derived from $O$. rufipogon accession GX2183) were used to map BPH36 and $B P H 27$ on chromosome 4 [BPH27 already reported by Huang et al. (2013) on Chromosome 4], and $B P H 36$ were fine mapped by using backcross population (Li et al. 2019). Recently, Yang et al. (2019) mapped a novel QTL BPH37 by using $\mathrm{F}_{2: 3}$ population derived from KWQZ/IR64 on chromosome 1, between RM 302 and YM35 markers. It is already reported that IR64 is harboring a major resistant gene $\mathrm{BPHI}$ on chromosome 12 and minor QTLs associated with BPH resistance, whereas BPH37 is a second major resistance locus was reported on chromosome 1. Although, unlike blast resistance genes, the cloned BPH resistance genes encode several kinds of proteins such as lectin kinase (BPH17), B3 DNA binding protein (BPH29), SCR domain (BPH32), and exocyst-localized unknown protein (BPH6), three popular BPH resistance genes (BPH26, BPH18, and BPH9) encode a member of coiled-coil-nucleotide-binding site-leucine-rich repeat (CC-NBS-LRR) (Du et al. 2009; Tamura et al. 2014; Liu et al. 2015; Wang et al. 2015; Ji et al. 2016; Ren et al. 2016; Zhao et al. 2016; Guo et al. 2018). This NBS-LRR protein family is involved in the activation of the salicylic acid (SA) dependent and jasmonic acid pathways that mediate sucking inhibition in the phloem sieve element and exhibits a high degree of resistance against different biotypes in India, Korea, and Japan. Hence, these BPH resistance genes encoding NBS-LRR protein family are being used in 
breeding programs to develop BPH resistant varieties (Suh et al. 2011; Ji et al. 2016; Jena et al. 2017).

Although significant achievements have been made in host-plant resistance to resist the attack of BPH by identifying and introgressing BPH resistance genes, the quick evolution of virulent BPH populations poses a primary concern (Naik et al. 2018). Hence, there is a need to explore more genetic variants from the diverse novel genes for building resistance to defend against the new virulent BPH populations to ultimately, attain durable and broad-spectrum resistance. To address these challenges, our study focused on (1) characterizing the resistance pattern of the parental lines and identifying novel BPH resistance sources (2) detecting the genomic regions conferring BPH resistance, and (3) selecting the introgression lines(ILs) possessing the highest similarity with the recurrent parent and donor genetic segment from a novel breeding strategy.

\section{Materials and methods}

Plant materials and development of mapping population

HHZ is a high-yielding indica variety, originated from Guangdong Province of China and used as the recurrent parent in our study (www.ricedata.cn/ variety/varis/600877.htm). The elite cultivar, Khazar originated from Gilan Province, Iran, was used as the donor parent. Taichung Native 1 (TN1) and IR62 were used as susceptible and resistant checks, respectively, for BPH phenotypic screening.

A cross was made between HHZ and Khazar to generate $F_{1}$ seeds, and the true $F_{1}$ plants were backcrossed with $\mathrm{HHZ}$ to obtain $\mathrm{BC}_{1} \mathrm{~F}_{1}$ plants. Initially, the derived $101 \mathrm{BC}_{1} \mathrm{~F}_{1}$ plants were subjected to bioassay to study the inheritance pattern of $\mathrm{BPH}$ resistance (Table 1). All the $101 \mathrm{BC}_{1} \mathrm{~F}_{1}$ plants were carefully rescued for generating $\mathrm{BC}_{1} \mathrm{~F}_{2}$ populations. These $\mathrm{BC}_{1} \mathrm{~F}_{2}$ plants advanced by the single seed descent (SSD) method until $\mathrm{BC}_{1} \mathrm{~F}_{5}$ mapping population. The $101 \mathrm{BC}_{1} \mathrm{~F}_{5}$ plants generated were subjected to phenotypic and genotypic characterization to explore the hidden genetic variability by identifying the genomic regions conferring $\mathrm{BPH}$ resistance. Further, these plants were rescued after bioassay and advanced to $\mathrm{BC}_{1} \mathrm{~F}_{6}$ for validation study, background analysis, and phenotypic selection for key agro-morphological traits (Fig. 1). All the $101 \mathrm{BC}_{1} \mathrm{~F}_{6}$ lines were utilized for validation and agronomic traits evaluation. A total of seven single $\mathrm{BC}_{1} \mathrm{~F}_{6}$ plants (six plants possessing homozygous dominant allele and one plant possessing homozygous receive allele) were selected out of $101 \mathrm{BC}_{1} \mathrm{~F}_{6}$ lines based on the phenotypic similarity with the recurrent parent and subjected for background genotyping. On the other hand, the same set of $101 \mathrm{BC}_{1} \mathrm{~F}_{2}$ plants and their progenies $\left(\mathrm{BC}_{1} \mathrm{~F}_{3}\right)$ underwent a $\mathrm{BPH}$ bioassay at the Indonesian Center for Rice Research (ICRR), Sukamandi, to evaluate the BPH resistance against Sukamandi BPH population (Fig. 2).

\section{Bioassay for the BPH resistance study}

To conduct the BPH bioassay, a local BPH colony collected from Laguna Province and belonging to biotype 3 (Saxena and Barrion 1985) was used. The pure Laguna BPH colony was developed from the single colony of BPH collected from Laguna Province of the Philippines. These colonies were reared and maintained on susceptible cultivar TN1 in the biotic stress screen house (BSSH) facility at IRRI. The bioassay was conducted by following the modified seedbox method (MSB) as described by Jena et al. (2006) at both $\mathrm{BC}_{1} \mathrm{~F}_{1}$ and $\mathrm{BC}_{1} \mathrm{~F}_{5}$ generations. Seedlings of the mapping population, the parental lines, and resistant and susceptible checks at two- to the threeleaf stage (seven days old) were infested with secondor third-instar nymphs at a density of 10-12 nymphs per seedling. A uniform number of seedlings at two- to three-leaf stage were maintained before the infestation to provide a similar opportunity for all the individuals of the test entries. Once the susceptible check (TN1)
Table 1 Genetic analysis of $\mathrm{BC}_{1} \mathrm{~F}_{1}$ mapping population

\begin{tabular}{lllllll}
\hline S. No & BPH reaction & \multicolumn{2}{l}{ Number of individuals } & O-E & $(\mathrm{O}-\mathrm{E})^{2}$ & $\chi^{2}=(\mathrm{O}-\mathrm{E})^{2} / \mathrm{E}$ \\
\cline { 3 - 5 } & & Observed (O) & Expected (E) & & \\
\hline 1 & $\mathrm{R}$ & 42 & 50 & 8 & 81 & 1.62 \\
2 & $\mathrm{~S}$ & 59 & 50 & 9 & 81 & 1.62 \\
\hline
\end{tabular}


Fig. 1 Breeding scheme to develop early backcross mapping population and their utilization

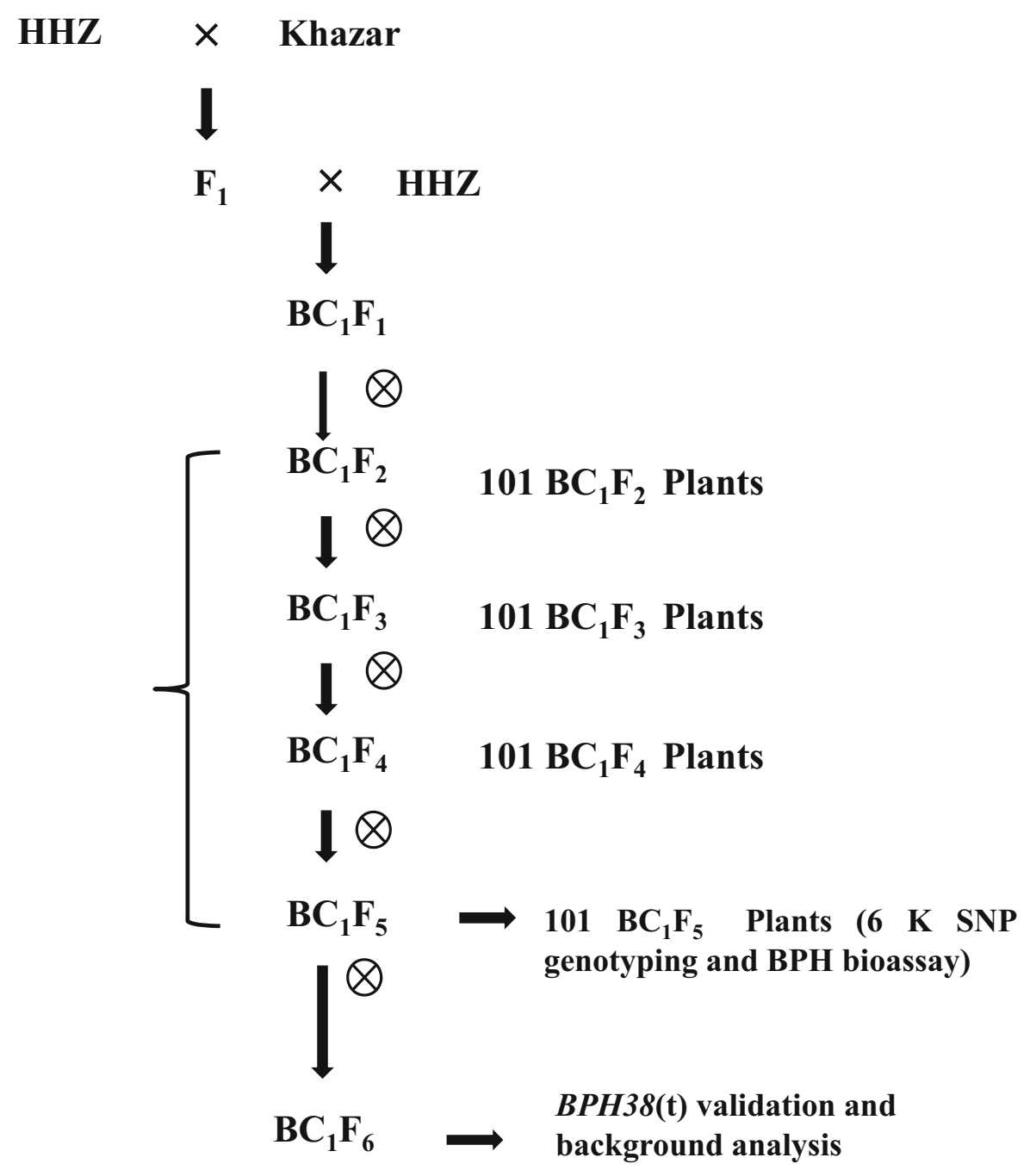

started wilting (90\%), data on seedling survival rate were recorded and finally expressed as a standard evaluation system (SES) score of 0-9 (IRRI 2014). Higher BPH scores indicate susceptibility and lower scores indicate the resistance response of the genotypes. The scoring pattern for BPH reaction is given in Supplementary Table 1 as mentioned in Prahalada et al. (2017).

High-resolution genotyping

The Infinium high-density SNP genotyping platform, 6 K SNP chip (Thomson et al. 2017), was used to carry out genotyping of the mapping population. This platform detects SNP alleles by adding fluorescencelabeled, allele-specific nucleotide (allele-specific hybridization) based on single-base extension and detection based on fluorescent color (https://www. ncbi.nlm.nih.gov/pmc/articles/PMC5577349/). Genotyping data were generated in a HapMap format. The obtained polymorphic SNP markers were filtered for no calls and unexpected mono- and heteromorphic SNPs between parents (Prahalada et al. 2017), and prepared according to the QTL IciMapping ver.4.0 input file requirement for linkage map construction and QTL analysis.

Linkage map construction and QTL mapping

A total of 702 high-quality SNP data points, filtered out from the $6 \mathrm{~K} \mathrm{SNP}$ chip, were used to construct the linkage map. The Kosambi mapping function was 


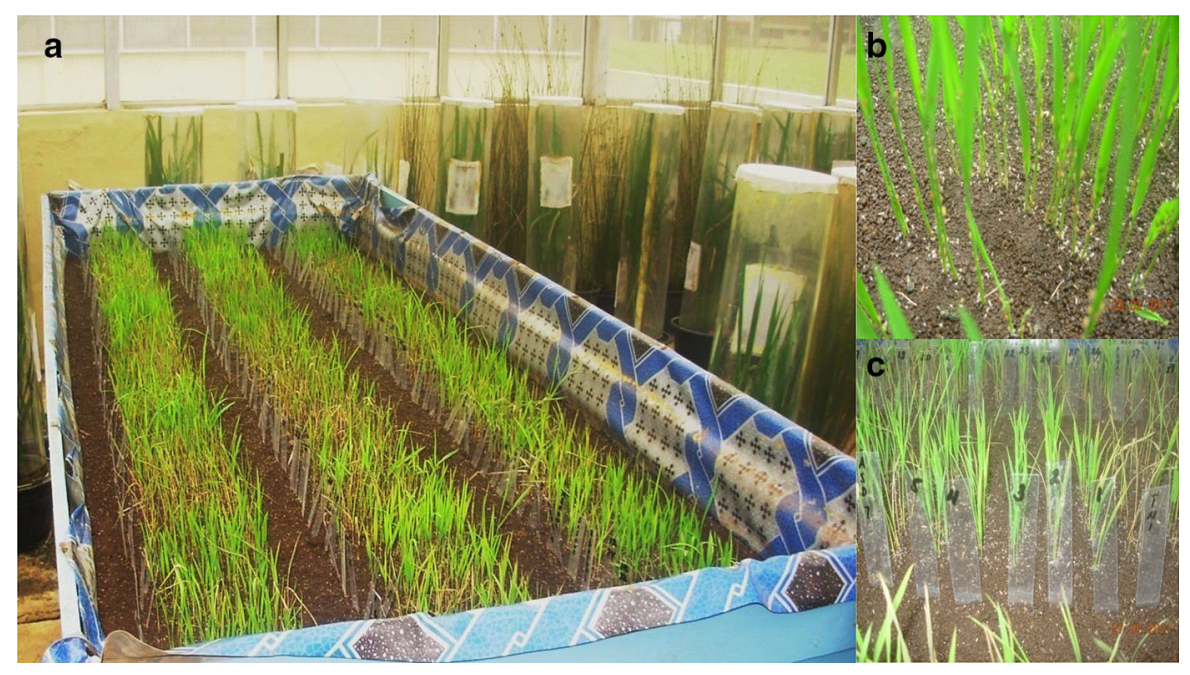

Fig. 2 Photographs showing BPH bioassay a experimental setup b infestation and $\mathbf{c}$ symptoms, conducted at ICRR, Sukamandi

used to convert recombination fraction into mapping distance to anchor markers to the specified location (Kosambi 1944). The linkage map construction was determined by using the QTL analysis software, QTL IciMapping version 4.0 (Meng et al. 2015). Further, QTL mapping was carried out by using the precisely estimated phenotypic BPH SES scores and genotypic data on SNP markers. Composite interval mapping, which is based on a multiple regression model of maximum likelihood with a 1000 permutation test at $P=0.05$, was used for the QTL analysis as it increases the statistical power and precision of the detected QTLs (Doerge and Churchill 1996; Prahalada et al. 2017; Mahender et al. 2019). LOD of 3.00 was considered as the threshold parameter for determining the significant QTLs among the detected QTLs.

\section{Post-QTL analysis}

In silico post-QTL analysis was performed based on the available information in rice databases: the MSU rice genome annotation project (https://rice. plantbiology.msu.edu/) and RiceXpro (https:// ricexpro.dna.affrc.go.jp/). In order to predict the candidate genes associated with a BPH resistance reaction, the candidate genes within the detected locus were listed based on the physical position of the flanking markers. Among the candidate genes, the one that was reported to be involved in biotic stress resistance was considered as a probable candidate gene conferring BPH resistance.
Evaluation of mapping populations for agromorphological traits

A total of $101 \mathrm{BC}_{1} \mathrm{~F}_{6}$ plants derived from $101 \mathrm{BC}_{1} \mathrm{~F}_{5}$ mapping population along with its parents were evaluated for the agro-morphological traits: days to $50 \%$ flowering (DFF), plant height (PH), tiller number $(\mathrm{TN})$, grain yield $(\mathrm{GY})$, and plot yield (PY). For the evaluation, a randomized complete block design (RCBD) was laid out, and the experiment was carried out with two replications in the 2017 wet season (WS). Each entry was planted in three rows, with 12 plants in each row having a space of $15 \times 20 \mathrm{~cm}$ between the plants and the rows. DFF was recorded based on the number of days from sowing to $50 \%$ flowering in a population on a whole-plot basis. PH was measured from the base of the plant to the tip of the tallest tiller. TN was counted from each plant to express the average TN per plant. The data were recorded from 10 competitive plants from each plot that are chosen at random, and the mean values were computed for different lines. GY per plant and 33 plants per plot were weighed after proper drying (moisture content $12 \%$ ) as described in Balachiranjeevi et al. (2018).

\section{Statistical analysis}

To analyze the extent of variation of the agromorphological traits among the test lines, descriptive statistics showing the range, standard deviation (SD), and standard error of the mean (SEm) at $P=0.05$ were 
used. The RCBD experimental design was used for conducting the bioassay and the agro-morphological evaluation considering four and two replications, respectively. Analysis of variance (ANOVA) was employed to assess the significance of the bioassay and agro-morphological evaluation at the level of significance $P=0.05$. DMRT and Fisher's t-test were used to determine the significant differences of the individual test entries for BPH resistance. Chi-square goodness of fit was used to analyze the segregation pattern of the markers and the phenotypic SES score. The multiple linear regression model of maximum likelihood was used to localize the genomic regions conferring BPH resistance (Prahalada et al. 2017).

\section{Results}

Bioassay and genetic analysis for BPH resistance

In order to study the mode of segregation of the BPH resistance derived from Khazar, genetic analysis was carried out. The parental lines (HHZ and Khazar) and their 101 derived $\mathrm{BC}_{1} \mathrm{~F}_{5}$ lines along with the resistant check IR62 and susceptible check TN1 were evaluated for BPH resistance using the MSB method during the WS of 2017. The parental lines HHZ and Khazar scored 9 and 3, indicating a susceptible and resistance $\mathrm{BPH}$ reactions, respectively (Fig. 3). Additionally, chi-square goodness of fit was employed to fit the $\mathrm{BPH}$ SES scores of $101 \mathrm{BC}_{1} \mathrm{~F}_{1}$ mapping populations for normal Mendelian segregation. Among $101 \mathrm{BC}_{1} \mathrm{~F}_{1}$ plants, 42 and 59 plants showed resistance and susceptible reaction respectively; and non-significance for the observed and expected ratios, indicating Mendelian inheritance $\left(\chi_{(0.52)}^{2}=1.62\right.$; Table 1$)$. Hence, from these results, it is evident that a single gene/locus confers BPH resistance derived from Khazar.

\section{Construction of a high-resolution linkage map}

A total of 4606 SNPs extracted from the Infinium $6 \mathrm{~K}$ SNP chip were processed before subjecting them to linkage map construction and QTL analysis. SNP markers processing involved filtration for no-call SNPs, unexpected heterozygous, and monomorphic SNPs between parents. A total of 195, 45, and 3664 SNP markers were found to be no calls, unexpected heterozygous and monomorphic SNP markers, respectively. Hence, these markers were filtered out to retrieve a total of 702 high-quality polymorphic SNP markers for further analysis (Table 2). These sets of markers were also analyzed for segregation distortion and were found that all these markers followed Mendelian segregation at the $P=0.05$ level of significance.

Furthermore, the filtered high-quality polymorphic SNP markers were used to construct the high-resolution linkage map. A total of 702 SNP markers were assigned to different chromosomes depending on the linkage distance. Chromosome 1 was covered by as many as 96 polymorphic markers. The highest number of SNP markers was found on chromosome 1, followed by chromosomes 3, 6, 7, 8, 11, 2, 5, 9, 4, 10 and 12. Apart from identifying the resolution of
Fig. 3 Photograph showing different levels of BPH resistance among the test lines in BPH bioassay on 9th day after BPH infestation. The numbers 1 to 12 shows the $\mathrm{BPH}$ reaction of sample test lines (1) susceptible check, TN1; (2) donor parent, Khazar; (3) recurrent parent, HHZ; and (7) resistant check, IR62; (4) to (6) and (8) to (12) are $\mathrm{BC}_{1} \mathrm{~F}_{5}$ individuals of mapping population lines

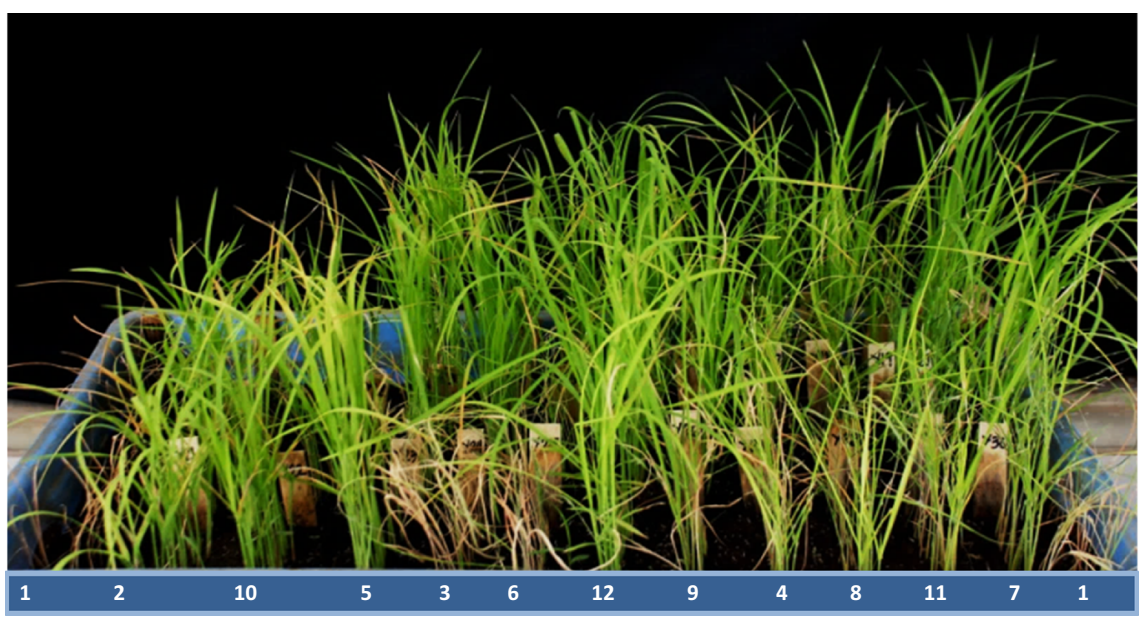


Table 2 Filtration of SNP markers extracted from Infinium 6 K SNP genotyping platform

\begin{tabular}{lccc}
\hline S. No & Description & $\begin{array}{l}\text { Total number of initial SNP } \\
\text { markers }\end{array}$ & $\begin{array}{l}\text { Total number of SNP markers after } \\
\text { filtration }\end{array}$ \\
\hline 1 & Initial markers & 4606 & - \\
2 & $\begin{array}{c}\text { Not amplified } \\
\text { markers }\end{array}$ & 195 & 4411 \\
3 & $\begin{array}{c}\text { Heterozygous } \\
\text { markers }\end{array}$ & 45 & 4366 \\
4 & $\begin{array}{c}\text { Monomorphic } \\
\text { markers }\end{array}$ & 3664 & 702 \\
Total polymorphic markers & & 702 \\
extracted & & \\
\hline
\end{tabular}

each chromosome, the percent polymorphism of SNP markers for each chromosome was also studied. The highest percent of polymorphism was attained for chromosome 1, followed by chromosomes 3 and 6 (Supplementary Table 2).

QTL analysis

The precisely estimated BPH SES scores of 101 $\mathrm{BC}_{1} \mathrm{~F}_{5}$ lines and genotypic data from high-quality SNP markers were used for the molecular mapping of the genomic regions conferring BPH resistance. Composite interval mapping with the 1000 permutation test was considered for the QTL analysis to make it more stringent. This analysis resulted in the identification of a putative locus showing as high as $35.91 \%$ PVE with LOD of 20.53. This locus was detected on chromosome 1 between SNP markers 693,369 and id $10,112,165$, between the physical positions $20,706,894 \mathrm{bp}$ and $21,203,101 \mathrm{bp}$ of $496.2 \mathrm{~kb}$ in size in the reference genome sequences of Nipponbare (IRGSP 1.0) (Table 3 and Fig. 4).
Background analysis and phenotypic evaluation of the selected $\mathrm{BC}_{1} \mathrm{~F}_{6}$ plants

Six out of seven selected $\mathrm{BC}_{1} \mathrm{~F}_{6}$ plants (from the 101 $\mathrm{BC}_{1} \mathrm{~F}_{6}$ lines \# LBS-004, LBS-009, LBS-011, LBS013, LBS-017, and LBS-020) were carrying homozygous dominant allele of $B P H 38(\mathrm{t})$ locus (RR) while one $\mathrm{BC}_{1} \mathrm{~F}_{6}$ plant (\# LBS-019) was carrying homozygous recessive allele (rr). All the seven $\mathrm{BC}_{1} \mathrm{~F}_{6}$ plants underwent background analysis using 702 SNP markers and were further evaluated to confirm their resistance reaction against $\mathrm{BPH}$ infestation. Background analysis was carried out to compute the percent recovery of the recurrent parent genome and size of the donor parent segment. The percent recovery of the recurrent parent genome ranged from 85.16 to $91.91 \%$ among the selected $\mathrm{BC}_{1} \mathrm{~F}_{6}$ lines possessing BPH38(t) locus. The IL LBS-013 showed the highest percent recovery of the recurrent parent genome (91.91\%), whereas LBS-017 showed the lowest percent recovery $(85.16 \%)$. However, except for line LBS-019, all other ILs showed the introgressed donor segment of $496.2 \mathrm{~kb}$ in size, thus confirming the introgression of the donor segment (Fig. 5). Hence, as expected, all of the ILs except for LBS-019 showed an

Table 3 Details of the identified BPH resistance locus, $B P H 38(\mathrm{t})$ detected from the $101 \mathrm{BC}_{1} \mathrm{~F}_{5}$ mapping population derived from $\mathrm{HHZ} \times$ Khazar

\begin{tabular}{|c|c|c|c|c|c|c|c|c|}
\hline Detected locus & Chromosome & Position (cM) & Left marker & Right marker & LOD & PVE $(\%)$ & Add & Dom \\
\hline$B P H 38(t)$ & 1 & 112 & 693,369 & id1012165 & 20.53 & 35.91 & -23.12 & 4.46 \\
\hline
\end{tabular}




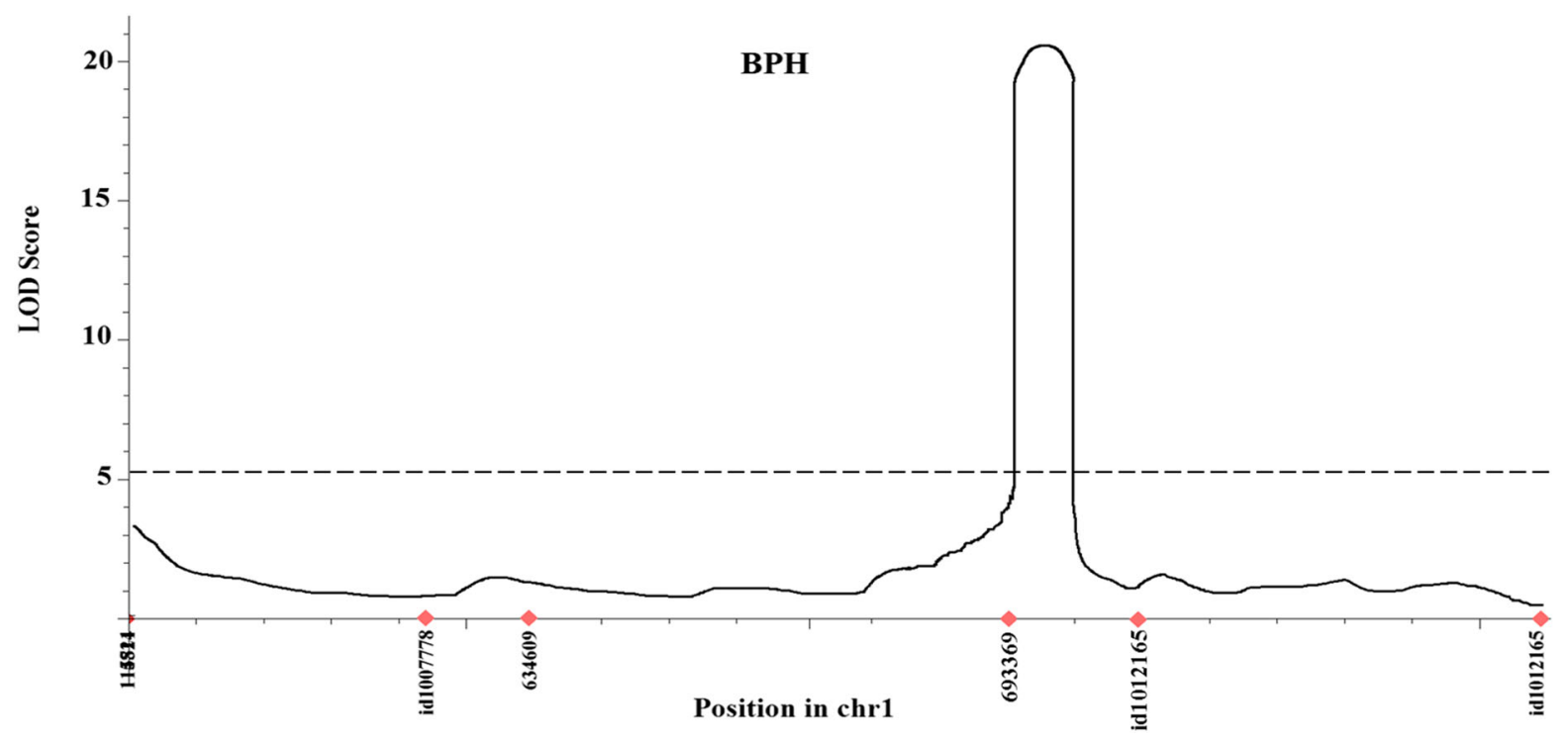

Fig. 4 QTL map showing the detected BPH resistance locus, $B P H 38(\mathrm{t})$ derived from $H H Z \times$ Khazar

\section{LBS-004}

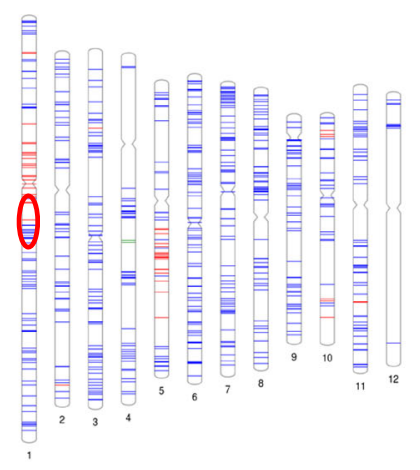

LBS-011

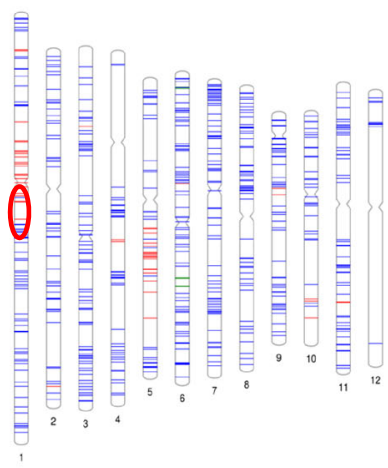

LBS-017

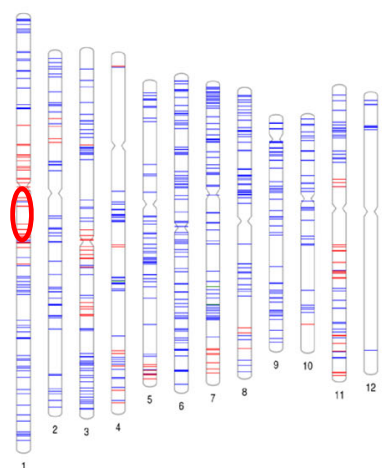

\section{LBS-020}

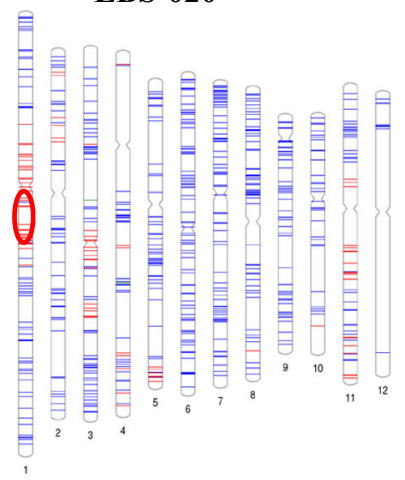

Fig. 5 Graphical genotype map of selected $\mathrm{BC}_{1} \mathrm{~F}_{6}$ plants. The map was constructed based on 702 high quality SNPs. LBS-004, LBS-011, LBS-017 and LBS-020 are the $\mathrm{BC}_{1} \mathrm{~F}_{6}$ genotypes
LBS-019

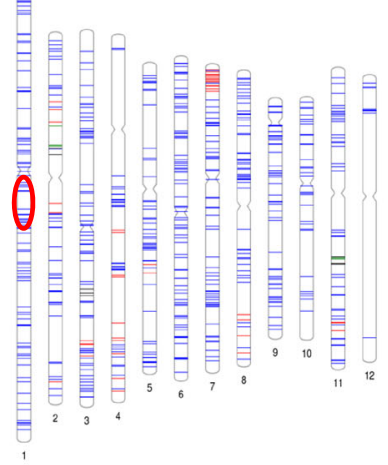

Blue color line indicates recurrent parent allele

Red color line indicates donor parent allele

Green color line indicates heterozygous allele

Red circle indicates BPH38(t) locus possessing $B P H 38(\mathrm{t})$ locus (positive ILs) whereas LBS-019 is the another $\mathrm{BC}_{1} \mathrm{~F}_{6}$ doesn't possess $B P H 38(\mathrm{t})$ locus (negative ILs). (Color figure online) 
SES score of 3, indicating a high $\mathrm{BPH}$ resistance reaction and as the effect of the detected BPH resistance locus (Table 4).

Further, the $101 \mathrm{BC}_{1} \mathrm{~F}_{6}$ individuals were evaluated to assess their performance for key agro-morphological traits such as DFF, PH, TN, GY, and PY, along with donor and recurrent parents (Table 5). All the selected ILs exhibited taller plant type ranging from $99.11 \mathrm{~cm}$ to $115.20 \mathrm{~cm}$ compared with the recurrent parent HHZ $(91.51 \mathrm{~cm})$. A significant difference was observed for TN per plant ranged from 12.61 to 14.81 , whereas the recurrent parent HHZ showed $12 \mathrm{TN}$ per plant. For GY per plant and PY, two ILs (LBS-011 and LBS-009) exhibited an advantage over HHZ. Three ILs (LBS-004, LBS-020, and LBS-013) were isophenic, and the remaining two ILs (LBS-017 and LBS019) showed significantly lower GY. For DFF, IL LBS-019 (80 days) showed significantly lower DFF than HHZ (94 days), as shown in Table 5.

Candidate gene analysis

In silico candidate gene analysis was performed by using online MSU and RiceXpro databases, and in these 71 candidate genes present within the vicinity of the flanking markers 693,369 and id 10,112,165 were retrieved. Most of them are expressed and retrotransposon proteins (Supplementary Table 3). Among all the candidate genes, LOC_OsO1g37260 is found near left SNP marker 693,369 (physical position $20,706,894 \mathrm{Mb}$ ) within a physical distance of $98.90 \mathrm{~kb}$. This gene encodes OsFBX14, an F-box protein of FBXL class containing the LRR domain, which is proven to be involved in biotic stress resistance (Jin et al. 2004; Jain et al. 2007). However, research is ongoing to test these candidate genes for their relevance in the phenotypic expression of $\mathrm{BPH}$ resistance.

\section{Discussion}

The increased density of BPH populations causes "hopper burn" symptom, which ultimately leads to complete death of rice plants (Prahalada et al. 2017). Although several strategies are available to manage $\mathrm{BPH}$ infestation, building $\mathrm{BPH}$ resistance in rice plants by identifying and introgressing $\mathrm{BPH}$ resistance genes is the most convenient and efficient strategy. To date, $37 \mathrm{BPH}$ resistance genes have been identified from cultivated and wild species of Oryza:BPH1, BPH2, ВPH3, ВPH4, ВPH5, ВРH6, ВРH7, ВРH8, BPH9, BPH10, BPH11(t), BPH12(t),BPH12, BPH13(t), BPH14, BPH15, BPH16(t), BPH17, BPH18, BPH19(t), BPH20, BPH21, BPH22(t), $B P H 23(\mathrm{t}), B P H 24(\mathrm{t}), \quad B P H 25(\mathrm{t}), \quad B P H 26(\mathrm{t}), B P H 27$, ВРH28, ВНР29,ВРН30, ВРН31, ВРН32,ВРН33, $B P H 3$ and $B P H 35, B P H 36$ and BPH37 (Khush et al. 1985; Kabis and Khush 1988; Nemoto et al. 1989; Ishii et al. 1994; Murata et al. 1998; Hirabayashi et al. 1998; Renganayaki et al. 2002; Yanget al. 2002; Sharma et al. 2003; Yang et al. 2004; Hirabayashi et al. 2004; Sun et al. 2005; Chang-Chao et al. 2006; Chen et al. 2006; Jena et al. 2006; Sai Harini et al 2010; Jairin et al. 2007, 2010; Li et al. 2019; Ram et al. 2008; Rahman et al. 2009; Du et al. 2009; Qiu et al. 2010; Deen et al. 2010; Qiu et al. 2012; Myint et al. 2012; Huang et al. 2013; Wu et al. 2014; Wang et al. 2015;

Table 4 Background analyses and BPH resistance score of advanced ILs derived from HHZ $\times$ Khazar

\begin{tabular}{|c|c|c|c|c|c|c|c|c|}
\hline \multirow{2}{*}{$\begin{array}{l}\text { S. } \\
\text { No }\end{array}$} & \multirow[t]{2}{*}{ Genotype } & \multirow{2}{*}{$\begin{array}{l}\text { Total polymorphic } \\
\text { SNP markers }\end{array}$} & \multicolumn{3}{|c|}{ Number of SNP allele } & \multirow{2}{*}{$\begin{array}{l}\text { Percentage of recurrent parent } \\
\text { genome recovered }\end{array}$} & \multirow{2}{*}{$\begin{array}{l}\text { BPH35(t) } \\
\text { locus }\end{array}$} & \multirow{2}{*}{$\begin{array}{l}\text { BPH SES } \\
\text { score }\end{array}$} \\
\hline & & & $\mathrm{HHZ}$ & Khazar & $\overline{\text { Hetero }}$ & & & \\
\hline 1 & LBS-004 & 702 & 642 & 56 & 2 & 91.85 & Presence & 3 \\
\hline 2 & LBS-011 & 702 & 637 & 58 & 6 & 91.29 & Presence & 3 \\
\hline 3 & LBS-017 & 701 & 595 & 102 & 4 & 85.16 & Presence & 3 \\
\hline 4 & LBS-020 & 702 & 605 & 95 & 2 & 86.32 & Presence & 3 \\
\hline 5 & LBS-009 & 702 & 634 & 54 & 8 & 91.66 & Presence & 3 \\
\hline 6 & LBS-013 & 702 & 639 & 53 & 7 & 91.91 & Presence & 3 \\
\hline 7 & LBS-019 & 702 & 638 & 47 & 13 & 92.33 & Absence & 7 \\
\hline
\end{tabular}


Table 5 Agronomic performance of selected ILs derived from HHZ $\times$ Khazar

\begin{tabular}{lllllll}
\hline S. No & Genotype & Plant height $(\mathrm{cm})$ & Tiller number & Grain yield $(\mathrm{g})$ & Plot yield $(\mathrm{Kg})$ & Days to 50\% heading \\
\hline 1 & LBS-004 & 112.40 & 13.80 & 298 & 0.30 & 114 \\
2 & LBS-011 & 108.20 & 14.40 & 532 & 0.53 & 116 \\
3 & LBS-017 & 99.00 & 14.80 & 223 & 0.22 & 114 \\
4 & LBS-020 & 104.80 & 12.60 & 292 & 0.29 & 112 \\
5 & LBS-009 & 110.40 & 13.40 & 459 & 0.46 & 114 \\
6 & LBS-013 & 106.80 & 13.40 & 285 & 0.29 & 114 \\
7 & LBS-019 & 115.20 & 13.20 & 205 & 0.21 & 80 \\
8 & HHZ & 91.50 & 12.00 & 290 & 0.29 & 94 \\
9 & IR50 & 96.33 & 15.20 & 387 & 0.39 & 109 \\
& SD & 5.78 & 1.39 & 28.41 & 0.15 & 2.29 \\
& SEm & 1.06 & 0.25 & 147.61 & 0.03 & 0.44 \\
& Range & 22.20 & 6.20 & 514.00 & 0.51 & 7.00 \\
\hline
\end{tabular}

Wang et al. 2018; Ren et al. 2016; Prahalada et al. 2017; Kumar et al. 2018; Naik et al. 2018; Yang et al. 2019; Yuexiong et al. 2019). Among these, only eight genes (BPH14, BPH17, BPH18, BPH26, BPH29, BPH9, BPH32, BPH31 and BPHO) were cloned and characterized (Du et al. 2009; Tamura et al. 2014; Liu et al. 2015; Wang et al. 2015; Ji et al. 2016; Ren et al. 2016; Zhao et al. 2016; Guo et al. 2018). However, most of the mapped resistance genes were only effective against a single BPH population/biotype (Horgan et al. 2015). Notably, several BPH resistance genes have been broken down by the evolution of new $\mathrm{BPH}$ biotypes, resulting in significant losses of rice production (Liu et al. 2015). Hence, it is imperative to identify new sources of BPH resistance and use them in a crop improvement program. In our study, we carried out high-resolution mapping of $\mathrm{BPH}$ resistance derived from Khazar and HHZ and mapped a new $\mathrm{BPH}$ resistance locus, $B P H 38(\mathrm{t})$, on the long arm of chromosome 1. This locus is located between SNP markers 693,369 and id 10,112,165, within the physical positions of $20.71 \mathrm{Mb}$ and $21.23 \mathrm{Mb}$ and having a size of $496.20 \mathrm{~kb}$. This is the third $\mathrm{BPH}$ gene reported on chromosome 1 after $B P H 33(\mathrm{t})$, which was reported by Naik et al. (2018) within the physical region of $24.52 \mathrm{Mb}$ and $25.51 \mathrm{Mb}$, and, recently, Yang et al. (2019) reported a novel QTL BPH35 on chromosome 1 between RM302 and YM35 markers with in a physical distance of $32.98 \mathrm{Mb}$ using IR64 as donor parent derived population. However, the location of the reported $B P H 38(\mathrm{t})$ locus in our study is novel as this is the first report on the detected locus from the donor. Early backcross generation $\mathrm{BC}_{1} \mathrm{~F}_{5}$ plants derived from the novel Green Super Rice breeding strategy were used for the localization of genomic regions conferring BPH resistance. Analogous to our study, several researchers also used early backcross progenies for molecular mapping for locating the genomic regions conferring several beneficial traits. Tamura et al. (1999) detected the Grhl gene on chromosome 1 by using a backcross population and applying RFLP markers and linkage mapping. Similarly, one of the most used broad-sense bacterial blight (BB) resistance genes, $\mathrm{Xa27}(\mathrm{t})$, was also identified using an early backcross generation. $\mathrm{Xa27}(\mathrm{t})$ was transferred from tetraploid wild rice Oryza minuta into cultivated $O$. sativa and is being used in several BB resistance breeding programs ( $\mathrm{Gu}$ et al. 2005).

The bioassay was conducted using the BPH colony collected from Laguna Province of the Philippines popularly called the Laguna colony. The bioassay revealed that the parent Khazar was the source for $\mathrm{BPH}$ resistance with a BPH SES score of 3 and the recurrent parent $\mathrm{HHZ}$ exhibited a susceptible reaction with a score of 9 . The individuals of the mapping population exhibited a wide range of BPH SES scores ranging from 3 to 9 . The frequency distribution of the SES scores of the mapping population showed a bimodal type of segregation, indicating Mendelian segregation of the BPH resistance. Furthermore, BPH 
resistance scores were tested for the chi-square goodness of fit, which also confirmed the monogenic inheritance of the $\mathrm{BPH}$ resistance factor $\left(\chi_{(0.52)}^{2}=1.62\right.$; Table 1$)$. This result is also supported by the QTL mapping result, which showed high LOD and PVE for the identified BPH38(t) (Table 3; Fig. 4).

Several studies describe the mechanism of BPH resistance by cloning and characterizing several BPH resistance genes. These studies describe the BPH resistance influenced by candidate genes and their association with the chemical composition of the phloem sap, especially primary and secondary dietary metabolites. Salicylic acid (SA) is one of the metabolites reportedly involved in the BPH resistance mechanism (Du et al. 2009). The first cloned BPH14 resistance gene and later cloned, $B P H 26, B P H 29$, $B P H 9$, and $B P H 18$ were found to be involved in triggering the induction of SA through the signaling pathway and callous deposition in the phloem tissues coupled with trypsin secretion, which causes inhibition of sucking in the phloem and, hence, resistance (Du et al. 2009; Liu et al. 2015; Wang et al. 2015; Zhao et al. 2016; Ji et al. 2016; Prahalada et al. 2017). Similar to these researches, we have also explored the detected BPH resistance locus to identify the probable candidate gene involved in BPH resistance by applying recent genomics and bioinformatics tools. A genomic segment of $B P H 38(\mathrm{t})$ of $496.20 \mathrm{~kb}$ in size mapped in this study contained a minimum of 71 candidate genes. Most of the candidate genes within the locus were reported to be an encoding group of retrotransposon proteins followed by expressed proteins and other different kinds of proteins that were not associated with any biotic resistance (Supplementary Table 3). Interestingly, in our current study, we have also found a candidate gene LOC_OsO1g37260, which is $\sim 90.61 \mathrm{~kb}$ near the detected $B P H 38(\mathrm{t})$ resistance locus that encodes for F-box protein. F-box proteins constitute a large family in eukaryotes and are characterized by a conserved F-box motif (approximately 40 amino acids) at their $\mathrm{N}$ terminus that interacts with Skp1p-cullin-F-box (SCF) protein, which is a major class of plant E3 ligases (Jain et al. 2007). The name F-box was given because it was identified first in the $\mathrm{N}$-terminal region of cycline $\mathrm{F}$ (Bai et al. 1994). The $\mathrm{C}$ terminus of F-box proteins generally contains one or several highly variable protein-protein interaction domains, including leucine-rich repeat (LRR) (Jin et al. 2004). Furthermore, there are 687 F-box proteins, and they have ten different domains, out of which FBLD and FBXL are the F-box protein subfamilies that possess the LRR domain in nine different categories (Jain et al. 2007). The candidate gene LOC_OsOlg37260 is one among those F-box proteins (https://rice.plantbiology.msu. edu/cgi-bin/ORF_infopage.cgi?orf=LOC_Os01g37260.1) that possesses the LRR domain at the interaction with the $\mathrm{C}$ terminus, which is reported to be involved in the salicylic acid signaling pathway to attain high BPH resistance which consequently acts as a defense against BPH attack (Yan et al. 2009; Ji et al. 2016). However, more observations and further research are needed to confirm the involvement of the candidate gene LOC_OsO1g37260 in the expression of BPH resistance.

The recurrent parent HHZ is a commercially released mega-variety, originating from Guangdong Province of China that is susceptible to BPH. The ILs were generated by introgressing the $B P H 38(\mathrm{t})$ locus and initially subjected to background analysis to select the lines with maximum recovery of the recurrent parent genome, and the same set of lines was used for the bioassay to study the effectiveness of the BPH38(t) locus. The ILs LBS-013 and LBS-004 showed $91.91 \%$ and $91.85 \%$ recurrent parent genome, respectively, and were found to possess the $B P H 38(\mathrm{t})$ locus. Notably, positive ILs possessing $B P H 38(\mathrm{t})$ exhibited a high level of $\mathrm{BPH}$ resistance compared with that of the background line HHZ. On the contrary, ILs without $B P H 38(\mathrm{t})$ showed a similar level of BPH reaction (susceptibility) as HHZ confirmed the efficacy of the $B P H 38(\mathrm{t})$ locus (Table 4; Fig. 5). These lines also showed superior yield and yield-associated traits, especially LBS-011 and LBS009, which showed the highest yield of 5.85 and $5.05 \mathrm{t}$ $\mathrm{ha}^{-1}$, respectively. On the other hand, the IL LBS-019 showed the highest recurrent parent genome recovery $(92.33 \%)$ without exhibiting any resistance against $\mathrm{BPH}$ as it did not carry the BPH38(t) locus and was also not superior in agro-morphological characters in comparison to ILs carrying the BPH38(t) locus (Table 5). One backcross was made and was followed by six generations of selfing, which led to the higher recurrent parent genome recovery levels (85.16-91.91\%) (Table 4; Hasan et al. 2015). Thus, our study not only detected a locus conferring BPH resistance but could also able to identify ILs that were ready to be used as breeding products. Hence, we 
strongly believe that the achievements of our study can help manage the BPH insect pests to a great extent.

Acknowledgements The authors acknowledge that this study was carried out by using Green Super Rice Project Funds (ID OPP1130530) for Zhikang Li, CAAS.

\section{Compliance with ethical standards}

Conflict of interest The authors declare no conflict of interest.

Open Access This article is distributed under the terms of the Creative Commons Attribution 4.0 International License (http:// creativecommons.org/licenses/by/4.0/), which permits unrestricted use, distribution, and reproduction in any medium, provided you give appropriate credit to the original author(s) and the source, provide a link to the Creative Commons license, and indicate if changes were made.

\section{References}

Bai C, Richman R, Elledge SJ (1994) Human cyclin F. EMBO J 13:6087-6098

Balachiranjeevi CH, Naik SB, Kumar VA et al (2018) Markerassisted pyramiding of two major, broad-spectrum bacterial blight resistance genes, $\mathrm{Xa21}$ and $\mathrm{Xa33}$ into an elite maintainer line of rice, DRR17B. PLoS ONE 13(10):e0201271. https://doi.org/10.1371/journal.pone. 0201271

Brar DS, Virk PS, Jena KK, Khush GS (2009) Breeding for resistance to planthoppers in rice. Planthoppers: new threats to the sustainability of intensive rice production systems in Asia. International Rice Research Institute, Los Baños, Philippines, pp 401-428

Cabauatan PQ, Cabunagan RC, Choi I-R (2009) Rice viruses transmitted by the brown planthopper Nilaparvata lugens Stål. Planthoppers: new threats to the sustainability of intensive rice production systems in Asia. International Rice Research Institute, Los Baños, Philippines, pp 357-368

Cha Y, Ji H, Yun D et al (2008) Fine mapping of the rice Bph1 gene, which confers resistance to the brown planthopper (Nilaparvata lugens Stal), and development of STS markers for marker-assisted selection. Mol Cells 26:146-151

Chang-Chao SU, Hu-Qu Z, Chun-Ming W et al (2006) SSR mapping of brown planthopper resistance gene Bph 9 in Kaharamana, an indica rice (Oryza sativa $\mathrm{L}$ ). Acta Genet Sin 33:262-268

Chen JW, Wang L, Pang XF, Pan QH (2006) Genetic analysis and fine mapping of a rice brown planthopper (Nilaparvata lugens Stål) resistance gene bph19(t). Mol Genet Genomics 275:321-329. https://doi.org/10.1007/s00438-0050088-2

Deen R, Ramesh K, Gautam SK et al (2010) Identification of new gene for BPH resistance introgressed from O. rufipogon. Rice Genet Newsl 25:70-72
Doerge RW, Churchill GA (1996) Permutation tests for multiple loci affecting a quantitative character. Genetics 142:285-294

Du B, Zhang W, Liu B et al (2009) Identification and characterization of Bph14, a gene conferring resistance to brown planthopper in rice. Proc Natl Acad Sci USA 106:22163-22168

Fujita D, Kohli A, Horgan FG (2013) Rice resistance to planthoppers and leafhoppers. Crit Rev Plant Sci 32(3):162-191

Gu K, Yang B, Tian D et al (2005) R gene expression induced by a type-III effector triggers disease resistance in rice. Nature 435:1122-1125

Guo JP, Xu CX, Wu D et al (2018) Bph6 encodes an exocystlocalized protein and confers broad resistance to planthoppers in rice. Nat Genet 50:297-306

Hasan MM, Rafii MY, Ismail MR et al (2015) Marker-assisted backcrossing: a useful method for rice improvement. Biotechnol Equip 29:237-254

Hirabayashi H, Ideta O, Sato H et al (2004) Identification of a resistance gene to brown planthopper derived from Oryza minuta in rice. Breed Res 6:285

Hirabayashi H, Angeles ER, Kaji R, et al (1998) Identification of brown planthopper resistance gene derived from $O$. officinalis using molecular markers in rice. Breed Sci 48:82-86

Horgan FG, Ramal AF, Bentur JS et al (2015) Virulence of brown planthopper (Nilaparvata lugens) populations from South and South East Asia against resistant rice varieties. Crop Prot 78:222-231

Huang D, Qiu Y, Zhang Y et al (2013) Fine mapping and characterization of $\mathrm{BPH} 27$, a brown planthopper resistance gene from wild rice (Oryza rufipogon Griff.). Theor Appl Genet 126:219-229. https://doi.org/10.1007/s00122-0121975-7

IRRI (2014) Standard evaluation system for rice (SES), 5th edn. International Rice Research Institute, Los Baños

Ishii T, Brar DS, Multani DS, Khush GS (1994) Molecular tagging of genes for brown planthopper resistance and earliness introgressed from Oryza australiensis into cultivated rice $O$. sativa. Genome 37:217-221. https://doi.org/ 10.1139/g94-030

Jain M, Nijhawan A, Arora R et al (2007) F-box proteins in rice: genome-wide analysis, classification, temporal and spatial gene expression during panicle and seed development, and regulation by light and abiotic stress. Plant Physiol 143:1467-1483

Jairin J, Phengrat K, Teangdeerith S et al (2007) Mapping of a broad-spectrum brown planthopper resistance gene, Bph3, on rice chromosome 6. Mol Breed 19:35-44

Jairin J, Sansen K, Wongboon W, Kothcharerk J (2010) Detection of a brown planthopper resistance gene bph4 at the same chromosomal position of Bph3 using two different genetic backgrounds of rice. Breed Sci 60:71-75. https://doi.org/10.1270/jsbbs.60.71

Jena KK, Hechanova SL, Verdeprado H et al (2017) Development of 25 near-isogenic lines (NILs) with ten $\mathrm{BPH}$ resistance genes in rice (Oryza sativa L.): production, resistance spectrum, and molecular analysis. Theor Appl Genet 130:2345-2360. https://doi.org/10.1007/s00122017-2963-8 
Jena KK, Jeung JU, Lee JH et al (2006) High-resolution mapping of a new brown planthopper $(\mathrm{BPH})$ resistance gene, $B p h 18(\mathrm{t})$, and marker-assisted selection for $\mathrm{BPH}$ resistance in rice (Oryza sativa L.). Theor Appl Genet 112:288-297. https://doi.org/10.1007/s00122-005-0127-8

Ji H, Kim SR, Kim YH et al (2016) Map-based cloning and characterization of the $\mathrm{BPH} 18$ gene from wild rice conferring resistance to brown planthopper (BPH) insect pest. Sci Rep 6:1-13. https://doi.org/10.1038/srep34376

Jin J, Cardozo T, Lovering CR et al (2004) Systematic analysis and nomenclature of mammalian F-box proteins. Genes Dev 18:2573

Kabis A, Khush GS (1988) Genetic analysis of resistance to brown planthopper in rice (Oryza sativa L.). Plant Breed 100:54-58

Khush GS (1979) Genetics of and breeding for resistance to the brown planthopper. Brown planthopper: threat to rice production in Asia. International Rice Research Institute, Los Baños, pp 321-332

Khush GS, Karim ANMR, Angeles ER (1985) Genetics of resistance of rice cultivar ARC10550 to Bangladesh brown planthopper teletype. J Genet 64:121-125

Kosambi DD (1944) The estimation of map distances from recombination values. Ann Eugenics 12:172-175

Kumar K, Sarao PS, Bhatia D et al (2018) High-resolution genetic mapping of a novel brown planthopper resistance locus, Bph34 in Oryza sativa L X Oryza nivara (Sharma \& Shastry) derived inter-specific ${ }_{\mathrm{F}} 2$ population. Theor Appl Genet 131:1163-1171. https://doi.org/10.1007/s00122018-3069-7

Li Z, Xue Y, Zhou H, et al (2019) High-resolution mapping and breeding application of a novel brown planthopper resistance gene derived from wild rice (Oryza. rufipogon Griff). Rice 12:41. https://doi.org/10.1186/s12284-019-0289-7

Liu Y, Wu H, Chen $\mathrm{H}$ et al (2015) A gene cluster encoding lectin receptor kinases confers broad-spectrum and durable insect resistance in rice. Nat Biotechnol 33:301-307. https://doi. org/10.1038/nbt.3069

Mahender A, Ali J, Prahalada GD et al (2019) Genetic dissection of developmental responses of agro-morphological traits under different doses of nutrient fertilizers using highdensity SNP markers. PLoS ONE 14(7):e0220066. https:// doi.org/10.1371/journal.pone.0220066

Meng L, Li H, Zhang L, Wang J (2015) QTL IciMapping: Integrated software for genetic linkage map construction and quantitative trait locus mapping in biparental populations. Crop J 3:269-283

Murata K, Fujiwara M, Kaneda C et al (1998) RFLP mapping of a brown planthopper (Nilaparvata lugens Stal) resistance gene bph2 of indica rice introgressed into a japonica breeding line "Norin-PL4". Genes Genet Syst 73:359-364. https://doi.org/10.1266/ggs.73.359

Myint KKM, Fujita D, Matsumura M et al (2012) Mapping and pyramiding of two major genes for resistance to the brown planthopper (Nilaparvata lugens [Stål]) in the rice cultivar ADR52. Theor Appl Genet 124:495-504. https://doi.org/ 10.1007/s00122-011-1723-4

Naik SB, Divya D, Sahu N et al (2018) A new gene Bph33(t) conferring resistance to brown planthopper (BPH), Nilaparvata lugens (Stål) in rice line RP2068-18-3-5. Euphytica $214: 53$
Nemoto H, Ikeda R, Kaneda C (1989) New genes for resistance to brown planthopper, Nilaparvata lugens Stal, in rice. Jpn J Breed 39:23-28

Normile D (2008) Reinventing rice to feed the world. Science 321:330-333

Prahalada GD, Shivakumar N, Lohithaswa HC et al (2017) Identification and fine mapping of a new gene, $B P H 31$ conferring resistance to brown planthopper biotype 4 of India to improve rice, Oryza sativa L. Rice 10:41. https:// doi.org/10.1186/s12284-017-0178-x

Qiu Y, Guo J, Jing S et al (2010) High-resolution mapping of the brown planthopper resistance gene Bph6 in rice and characterizing its resistance in the 9311 and Nipponbare near isogenic backgrounds. Theor Appl Genet 121:1601-1611. https://doi.org/10.1007/s00122-010-1413-7

Qiu Y, Guo J, Jing S et al (2012) Development and characterization of japonica rice lines carrying the brown planthopper-resistance genes BPH12 and BPH6. Theor Appl Genet 124:485-494. https://doi.org/10.1007/s00122-011-1722-5

Rahman ML, Jiang W, Chu SH et al (2009) High-resolution mapping of two rice brown planthopper resistance genes, $B p h 20(t)$ and Bph21(t), originating from Oryza minuta. Theor Appl Genet 119:1237-1246. https://doi.org/10. 1007/s00122-009-1125-z

Ram T, Deen R, Gautam S et al (2008) Identification of new genes for brown planthopper resistance in rice introgressed from $O$. glaberrima and O. minuta. Rice Genet Newsl 25:67-68

Ray DK, Mueller ND, West PC, Foley JA (2013) Yield trends are insufficient to double global crop production by 2050 . PLoS ONE 8:e66428

Ren J, Gao F, Wu X et al (2016) Bph32, a novel gene encoding an unknown SCR domain-containing protein, confers resistance against the brown planthopper in rice. Sci Rep 6:1-14. https://doi.org/10.1038/srep37645

Renganayaki K, Fritz AK, Sadasivam S et al (2002) Mapping and progress toward map-based cloning of brown planthopper biotype-4 resistance gene introgressed from Oryza officinalis into cultivated rice, $O$ sativa. Crop Sci 42:2112-2117. https://doi.org/10.2135/cropsci2002.2112

Sai Harini A, Santhana Lakshmi S, Sai Kumar S et al (2010) Validation and fine-mapping of genetic locus associated with resistance to brown planthopper [Nilaparvata lugens (Stal.)] in rice (Oryza sativa L.). Asian J Bio Sci 5(1):32-37.

Saxena RC, Barrion AA (1985) Biotypes of the brown planthopper Nilaparvata lugens (Stål) and strategies in deployment of host plant resistance. Int J Trop Insect Sci 6:271-289

Seck PA, Diagne A, Mohanty S, Wopereis MCS (2012) Crops that feed the world 7: rice. Food Secur 4:7-24

Sharma N, Ketipearachchi Y, Murata K et al (2003) RFLP/ AFLP mapping of a brown planthopper (Nilaparvata lugens Stal) resistance gene Bph1 in rice. Euphytica 129:109-117. https://doi.org/10.1023/A:1021514829783

Sogawa K (1982) The rice brown planthopper: feeding physiology and host plant interactions. Annu Rev Entomol 27:49-73

Sogawa K, Liu GJ, Shen JH (2003) A review on the hypersusceptibility of Chinese hybrid rice to insect pests. Chin J Rice Sci 17:23-30 
Suh J-P, Yang S-J, Jeung J-U et al (2011) Development of elite breeding lines conferring Bph18 gene-derived resistance to brown planthopper (BPH) by marker-assisted selection and genome-wide background analysis in japonica rice (Oryza sativa L.). Field Crops Res 120:215-222

Sun L, Su C, Wang C et al (2005) Mapping of a major resistance gene to the brown planthopper in the rice cultivar Rathu Heenati. Breed Sci 55:391-396. https://doi.org/10.1270/ jsbbs.55.391

Tamura K, Fukuta Y, Hirae M et al (1999) Mapping of the Grh1 locus for green rice leafhopper resistance in rice using RFLP markers. Breed Sci 49:11-14

Tamura Y, Hattori M, Yoshioka H et al (2014) Map-based cloning and characterization of a brown planthopper resistance gene BPH26 from Oryza sativa L ssp indica cultivar ADR52. Sci Rep 4:5872

Tanaka K, Endo S, Kazano H (2000) Toxicity of insecticides to predators of rice planthoppers: spiders, the mirid bug and the dryinid wasp. Appl Entomol Zool 35:177-187

Thomson MJ, Singh N, Dwiyanti MS et al (2017) Large-scale deployment of a rice $6 \mathrm{~K} \mathrm{SNP}$ array for genetics and breeding applications. Rice. https://doi.org/10.1186/ s12284-017-0181-2

Wang Y, Cao L, Zhang Y et al (2015) Map-based cloning and characterization of $\mathrm{BPH} 29$, a B3 domain-containing recessive gene conferring brown planthopper resistance in rice. J Exp Bot 66:6035-6045. https://doi.org/10.1093/jxb/ erv318

Wang H, Shi S, Guo Q et al (2018) High-resolution mapping of a gene conferring strong antibiosis to brown planthopper and developing resistant near-isogenic lines in 9311 background. Mol Breed 38:107. https://doi.org/10.1007/ s11032-018-0859-1
Wu H, Liu Y, He J et al (2014) Fine mapping of brown planthopper (Nilaparvata lugens Stål) resistance gene Bph28(t) in rice (Oryza sativa L.). Mol Breed 33:909-918. https://doi.org/10.1007/s11032-013-0005-z

Yan J, Zhang C, Gu M et al (2009) The Arabidopsis CORONATINE INSENSITIVE1 protein is a jasmonate receptor $^{\mathrm{CW}}$. Plant Cell 21:2220-2236

Yang H, Ren X, Weng Q et al (2002) Molecular mapping and genetic analysis of a rice brown planthopper (Nilaparvata lugens Stål) resistance gene. Hereditas 136:39-43

Yang H, You A, Yang Z et al (2004) High-resolution genetic mapping at the Bph15 locus for brown planthopper resistance in rice (Oryza sativa L.). Theor Appl Genet 110:182-191. https://doi.org/10.1007/s00122-004-1844-0

Yang M, Cheng L, Yan L et al (2019) Mapping and characterization of a quantitative trait locus resistance to the brown planthopper in the rice variety IR64. Hereditas 156:22. https://doi.org/10.1186/s41065-019-0098-4

Yuexiong Z, Gang QIN, Qianqian MA et al (2019) Identification of a major resistance locus Bph35 to brown planthopper in rice (Oryza sativa L.). RICE SCI 2. http://www. ricescience.org/EN/abstract/abstract9847.shtml

Zhao Y, Huang J, Wang Z et al (2016) Allelic diversity in an NLR gene $B P H 9$ enables rice to combat planthopper variation. Proc Natl Acad Sci USA 113:12850-12855. https://doi.org/10.1073/pnas.1614862113

Publisher's Note Springer Nature remains neutral with regard to jurisdictional claims in published maps and institutional affiliations. 